Check for updates

Cite this: Phys. Chem. Chem. Phys., 2020, 22, 2685

Received 14th June 2019 Accepted 15th October 2019

DOI: $10.1039 / c 9 c p 03374 b$

rsc.li/pccp

\section{Direct observation of the electronic states of photoexcited hematite with ultrafast 2 p3d X-ray absorption spectroscopy and resonant inelastic $\mathrm{X}$-ray scattering $\dagger$}

\author{
Ahmed S. M. Ismail, (DD $\ddagger^{a}$ Yohei Uemura, (D) $\ddagger^{\text {ab }}$ Sang Han Park, $\ddagger^{c}$ Soonnam Kwon, \\ Minseok Kim, ${ }^{c}$ Hebatalla Elnaggar, ${ }^{a}$ Federica Frati, ${ }^{a}$ Yasuhiro Niwa, ${ }^{d}$ Hiroki Wadati, ${ }^{\circ}$ \\ Yasuyuki Hirata, ${ }^{e}$ Yujun Zhang, ${ }^{e}$ Kohei Yamagami, ${ }^{e}$ Susumu Yamamoto, \\ Iwao Matsuda, ${ }^{e}$ Ufuk Halisdemir, ${ }^{9}$ Gertjan Koster, ${ }^{9}$ Bert M. Weckhuysen (D) ${ }^{a}$ and \\ Frank M. F. de Groot*a
}

\begin{abstract}
Hematite, $\alpha-\mathrm{Fe}_{2} \mathrm{O}_{3}$, is an important semiconductor for photoelectrochemical water splitting. Its low charge carrier mobility and the presence of midgap states provide favourable conditions for electronhole recombination, hence affecting the semiconductor's photoelectrochemical efficiency. The nature of the excited state and charge carrier transport in hematite is strongly debated. In order to further understand the fundamental properties of the hematite photoexcited state, we conducted femtosecond $2 p\left(L_{3}\right) X$-ray absorption (XAS) and $2 p 3 d$ resonant inelastic scattering (RIXS) measurements on hematite thin-films at the Pohang Accelerator Laboratory X-ray Free Electron Laser (PAL-XFEL). The observed spectral changes and kinetic processes are in agreement with previous 3p XAS reports. The potential additional information that could be acquired from $2 \mathrm{p} 3 \mathrm{~d}$ RIXS experiments is also discussed
\end{abstract}

\section{Introduction}

X-ray absorption spectroscopy (XAS) combined with the pumpprobe method has become a powerful technique to investigate electronic states of photocatalytic materials..$^{1-4}$ XAS provides information on the element specific electronic structure of the material under investigation. In addition, XAS can be measured under operando conditions. ${ }^{5,6}$ In combination with calculations, XAS enables the determination of the detailed local structure

\footnotetext{
${ }^{a}$ Inorganic Chemistry and Catalysis, Debye Institute for Nanomaterials Science, Utrecht University, Universiteitslaan 99, 3584 CG Utrecht, The Netherlands. E-mail:f.m.f.degroot@uu.nl

${ }^{b}$ Institute for Catalysis, Hokkaido University, Kita 21 Nishi 10, Kita-ku, Sapporo, Hokkaido 001-0021, Japan

CAL-XFEL, Pohang Accelerator Laboratory, 77 Cheongam-Ro, Nam-Gu, Pohang, Gyeongbuk 37673, South Korea

${ }^{d}$ Photon Factory, Institute for Materials Structure Science, KEK, Tsukuba 305-0801, Japan

${ }^{e}$ Institute for Solid State Physics, University of Tokyo, Kashiwa, Chiba 277-8581, Japan

${ }^{f}$ Graduate School of Material Science, University of Hyogo, Kamigori, Hyogo 678-1297, Japan

${ }^{g}$ Faculty of Science and Technology and MESA + Institute for Nanotechnology, University of Twente, P.O. Box 2171, 7500 AE Enschede, The Netherlands

$\dagger$ Electronic supplementary information (ESI) available. See DOI: 10.1039/c9cp03374b

\$ These authors contributed equally to this work.
}

and electronic states of materials. ${ }^{7,8}$ There have been pioneering studies to investigate photoexcited states of metal oxides with the pump-probe XAS methodology., ${ }^{7,9-16}$ While synchrotron pump probe XAS experiments are limited by the pulse duration of X-rays $(\sim 100 \mathrm{ps})$ or by the reachable flux for slicing experiments, the birth of X-ray free electrons lasers (XFEL) has expanded the horizon of the time resolved studies based on the pump-probe XAS methodology. ${ }^{1,9,11,17-20}$ XFELs can provide ultrashort and intense X-ray pulses down to $10 \mathrm{fs}$. The number of photons in an X-ray pulse from XFELs are at least millions of times larger than that of an X-ray pulse in a synchrotron. Such short pulse duration has enabled the study of femtosecond dynamics, which have also been achieved with femtosecond optical laser spectroscopies. In addition to the capability of tracking ultrafast dynamics, such high intense X-ray pulses enable sophisticated photon-in/photon-out spectroscopic measurements such as X-ray emission spectroscopy (XES) ${ }^{21-23}$ and resonant inelastic X-ray scattering (RIXS) ${ }^{24-30}$ with a very short temporal resolution. RIXS spectra provide additional opportunities to observe electronic excitations in materials, which would be impossible only with optical spectroscopies. At PAL-XFEL, ${ }^{31,32}$ one can measure the $\mathrm{L}_{3}$ XAS of $3 \mathrm{~d}$ transition metal elements with a time resolution of less than $300 \mathrm{fs}^{33}$ In addition, $1 \mathrm{eV}$ resolved 2p3d RIXS ${ }^{34-36}$ can also be measured, which extends the information provided on the electronic states of $3 \mathrm{~d}$ metals. 
Here, we report the first time resolved $\mathrm{L}_{3}$ XAS and 2p3d RIXS experiments in PAL-XFEL to observe the photoexcited state of hematite $\left(\alpha-\mathrm{Fe}_{2} \mathrm{O}_{3}\right)$.

Hematite is intensely studied as a semiconductor for the solar-assisted water splitting processes. This is mainly due to its rich abundance in the earth crust and to its optical bandgap of $\sim 2 \mathrm{eV}$ that enables it to absorb light in the visible wavelength range of the solar spectrum. ${ }^{37,38}$ However, the intrinsic electronic properties of hematite make it difficult for the semiconductor to carry out the water splitting reaction directly, since its hole diffusion length is so small, $2-4 \mathrm{~nm}$, that the electrons and holes can easily recombine in short time scales. ${ }^{39,40}$ Therefore, ultrafast spectroscopic investigations of the nature of the hematite photoexcited states have gained increasing interest due to its relevance to its water splitting efficiency. ${ }^{12,38,41-43}$ For example, Vura-Weiss et al. conducted the first femtosecond extreme-ultra violet (XUV) spectroscopic studies on hematite thin films and reported that the observed photoinduced $\mathrm{Fe}$ (II) states originate mainly from ligand to metal charge transfer (LMCT) i.e. the charge transfer from oxygen to iron, and not from the optical d-d excitation. ${ }^{44}$ Further theoretical and experimental XUV spectroscopic reports suggested that an additional reason for the low hematite performance is the formation of small polarons that localize the minority carriers at recombination centres. $^{45,46}$

Our time resolved studies of $2 \mathrm{p}$ X-ray absorption spectroscopy (XAS) and 2p3d resonant inelastic X-ray scattering (RIXS) of iron elucidate the electronic structure of the photoexcited hematite. The results also demonstrate the potential of $2 \mathrm{p} 3 \mathrm{~d}$ RIXS experiments to understand the electronic nature of excited states in photocatalytic materials.

\section{Experiments and calculations}

\section{Sample preparation}

A $50 \mathrm{~nm}$ hematite $\left(\alpha-\mathrm{Fe}_{2} \mathrm{O}_{3}\right)$ polycrystalline thin-film was prepared on indium tin oxide (ITO)/fused silicon dioxide substrate by pulsed laser deposition (PLD). First, a $5 \mathrm{~nm}$ ITO thin film was deposited on a fused silicon dioxide substrate by translating a $\mathrm{KrF}$ excimer laser $(\lambda=248 \mathrm{~nm})$ on a rotating ITO target with an incident angle of $45^{\circ}$ with a fluency of $2 \mathrm{~J} \mathrm{~cm}^{-2}$ and a repetition rate of $1 \mathrm{~Hz}$. The ITO target was then replaced with hematite target and hematite thin-film was deposited at the same deposition conditions. The deposition experiment was conducted at $700{ }^{\circ} \mathrm{C}$ and under $1.3 \mathrm{kPa}$ oxygen pressure. The average surface roughness of the hematite thin-film was determined to be $4.7 \mathrm{~nm}$ using Atomic Force Microscopy. X-ray Photoelectron Spectroscopy (XPS) was employed to confirm iron and oxygen electronic properties in hematite. Further information on the sample characterization can be found in the ESI. $\dagger$

\section{The X-ray setup at PAL-XFEL}

All XAS and RIXS spectra were measured in the soft X-ray spectroscopy and scattering (SSS) beamline of PAL-XFEL. An illustration of the SSS beamline of PAL-XFEL is shown in Fig. 1.

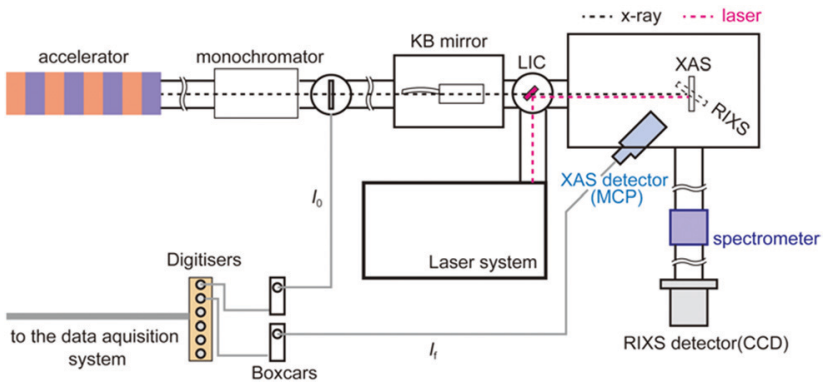

Fig. 1 The experimental setup of the SSS beamline of PAL-XFEL. A microchannel plate (MCP) detector was employed to measure fluorescent $X$-ray and a CCD detector was employed to measure RIXS signals.

In the SSS beamline, soft X-rays between $250 \mathrm{eV}$ and $1200 \mathrm{eV}$ are available. In order to monochromatise the X-ray, a grating optics with 200 lines per $\mathrm{mm}$ was employed and the estimated energy resolution of the monochromatised X-ray was about $0.5 \mathrm{eV}$ at $710 \mathrm{eV}$ for the XAS experiments and about $1.0 \mathrm{eV}$ for the RIXS experiments at $710 \mathrm{eV}$. The monochromatised X-ray was focused by a pair of Kirkpatrik-Baez mirrors to reduce the X-ray size to less than $50 \mu \mathrm{m}(H) \times 50 \mu \mathrm{m}(V)$ on the sample position. Since the X-ray intensities are different in each X-ray pulse, it was necessary to measure the monochromatised X-ray intensity $\left(I_{0}\right)$ and the fluorescent X-ray intensity $\left(I_{\mathrm{f}}\right)$ shot by shot in order to obtain XAS correctly. Each $I_{0}$ intensity was observed by the electrons emitted from a $\mathrm{Si}_{3} \mathrm{~N}_{4}$ thin-film. The photoelectrons were measured with a microchannel plate (MCP) detector. The $I_{\mathrm{f}}$ intensity was measured with another MPC detector by obtaining fluorescent X-ray photons from the sample. Two boxcar integrators (SR250, Stanford Research Systems) were employed to collect both the signals from the MCP detectors. The boxcar integrators were synchronised with the trigger signals from the XFEL in order to gather only the signals from the X-ray pulses. The output signals from the boxcars were transferred to the digitizers (SR245, Stanford Research Systems). A Ti:sapphire laser was employed to excite the sample. Its fundamental wavelength was converted to $400 \mathrm{~nm}$ with a BBO crystal. The laser pulses were transferred into the measurement chamber and focused on the sample position. The spot size of the laser was approximately $210 \mu \mathrm{m}(H) \times 210 \mu \mathrm{m}(V)$ for its $1 / e^{2}$ value. The angle between the X-ray and the laser was set to about $1^{\circ}$. The excitation laser fluence was set to $\sim 8 \mathrm{~mJ} \mathrm{~cm}^{-1}$, which was found to be the optimum laser fluence for exciting $\sim 20 \%$ of the iron atoms and in the same time causing minimal to no sample damage or nonlinear effects.

\section{The X-ray setup at Spring-8}

Transient XAS spectra of the $\mathrm{Fe} \mathrm{L}_{3}$ edge in the picoseconds regime were measured at the BL07LSU beamline in SPring-8. ${ }^{47}$ During the beamtime, the operation mode of SPring- 8 was "H-mode", ${ }^{48}$ where one electron bunch between bunch trains is detected. The X-rays from the isolated bunch arrives every $\sim 4.76 \mu \mathrm{s}(\sim 210 \mathrm{kHz})$. In order to synchronise with the excitation laser $(\sim 1 \mathrm{kHz})$, an X-ray chopper was employed to select X-ray pulses. XAS spectra were measured in a Partial Electron Yield 
(PEY) geometry. An MCP detector was employed to measure the intensity of electrons coming out from the sample surface. The fluence of the excitation laser was the same as in PAL-XFEL and the temporal resolution of the set up was estimated to be $80 \mathrm{ps}$. Further details on the setup were explained in ref. 47.

\section{Theoretical calculations}

The X-ray absorption and X-ray emission processes have been modelled with crystal field multiplet theory. The use of the charge transfer multiplet (CTM) model is based on the argument that the $2 \mathrm{p}$ core hole state is localised on one site allowing a local model to describe the $2 \mathrm{p} 3 \mathrm{~d}$ excitation and the $3 \mathrm{~d} 2 \mathrm{p}$ X-ray emission decay. The $2 \mathrm{p}$ XAS spectra are simulated from transitions from the $3 \mathrm{~d}^{5}$ ground state to the $2 \mathrm{p}^{5} 3 \mathrm{~d}^{6}$ final state, which are based on the model described by de Groot et al. and Vura-Weiss et al. ${ }^{44,50}$ The parameters we used for the calculations are identical to the parameters used in these studies, i.e. atomic values are used for the electron-electron interactions and spin-orbit couplings and a value of $0.5 \mathrm{eV}$ was used for the octahedral crystal field. The multiplet-averaged $\mathrm{Fe}(\mathrm{II})$ calculation is shifted by $0.7 \mathrm{eV}$ with respect to $\mathrm{Fe}(\mathrm{III})$, following the experimentally determined shift between $\mathrm{Fe}(\mathrm{II})$ and $\mathrm{Fe}(\mathrm{III})$ sites in $\mathrm{CoFe}_{2} \mathrm{O}_{4} \cdot{ }^{51}$

\section{Results and discussion}

\section{2p X-ray absorption spectroscopy of photoexcited hematite}

The Fe $\mathrm{L}_{3}$ edge XAS spectrum and transient (difference) spectra of hematite are shown in Fig. 2. Each difference spectrum was calculated by subtracting the reference spectrum (the spectrum at a delay time of $-10 \mathrm{ps}$ ) from the photoexcited XAS spectrum at the corresponding delay time. A distinctive change was observed at $709 \mathrm{eV}$ in the difference XAS spectra at positive

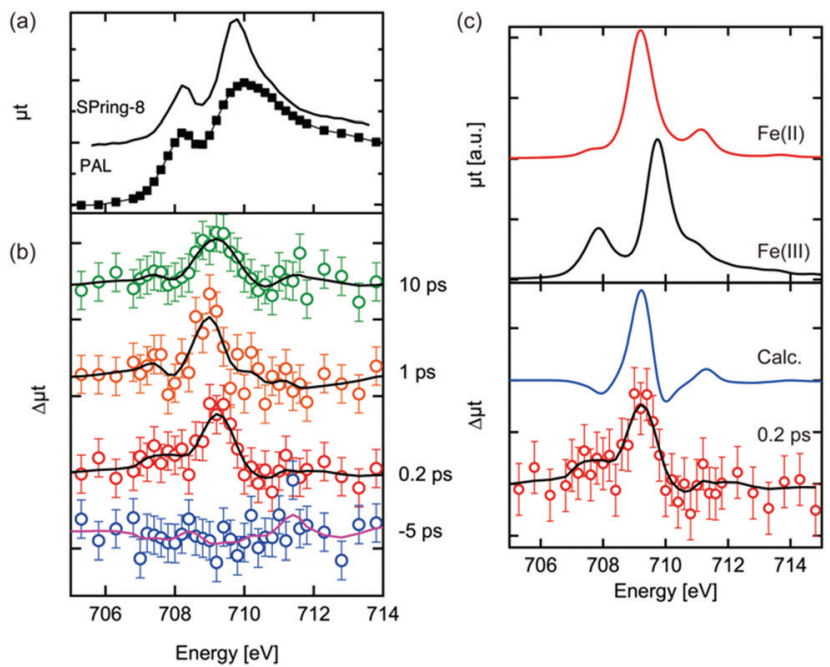

Fig. 2 Fe $L_{3}$ edge XAS spectrum of the hematite thin film (a), the transient Fe $L_{3}$ edge XAS spectra of photoexcited hematite at several delay times (b) and the calculated spectra of $\mathrm{Fe}_{3}$ edge XAS by the multiplet theory. The solid black line in panel (c) is the smoothed representation of the experimental data points that helps to clarify the spectral shape of the transient spectra. delay times. The maximum of the peaks around $709 \mathrm{eV}$ in each difference spectrum at a positive delay time are comparable to each other, while the peak width at a delay time of $10 \mathrm{ps}$ is larger. It is expected that the laser excites electrons in the Fe $3 \mathrm{~d}$ orbitals, effectively reducing $\mathrm{Fe}(\mathrm{III})$ to $\mathrm{Fe}(\mathrm{II})$. Vura-Weis et al. have observed the excited state of hematite with transient $3 \mathrm{p}$ XAS experiments and they calculated the XAS spectra of the excited states with multiplet calculations. ${ }^{44}$ Similar calculations of the 2p XAS spectra of Fe(II) were performed by de Groot et al. and Haverkort et al. ${ }^{49,50}$ The difference spectra between the calculated $\mathrm{Fe}_{3}$ XAS of $\mathrm{Fe}(\mathrm{II})$ and the calculated the XAS of $\mathrm{Fe}(\mathrm{III})$ are shown in Fig. 2(c). The XAS spectra of Fe(II) were scaled in order to reproduce the spectral shapes of the difference XAS $\left(\Delta \mu t_{\text {calc }}=\mu t_{\mathrm{Fe}(\mathrm{II})}(E+\Delta E)-\alpha \mu t_{\mathrm{Fe}(\mathrm{III})}(E)\right)$. We estimated the values of $\alpha$ and $\Delta E$ value based on the knowledge of XAS of the mixed-valence iron compounds such as $\mathrm{Fe}_{3} \mathrm{O}_{4}$, where a detailed fitting procedure determined a shift between octahedral Fe(II) and octahedral Fe(III) to be $0.7 \mathrm{eV} .{ }^{51}$ Different $\alpha$ values were explored in order to reproduce the spectral features of the difference XAS. The combination of $\alpha=0.5$ and $\Delta E=0.7 \mathrm{eV}$ were found to be the best values to reproduce the experimental spectra. The main peak position of the difference spectra in Fig. 2(b) was reproduced by the calculated spectra. The photoexcited state at a delay time of $0.2 \mathrm{ps}$ is the initial excited state and is equal to the time resolution of our experiment as shown below in Fig. 3(b). We expect that no structural change occurs at this time scale, implying that the crystal field value $10 \Delta_{\mathrm{q}}$ can be approximated as being equal to the ground state value of Fe(III).

\section{Kinetic traces of 2p3d X-ray absorption spectroscopy of photoexcited hematite}

The kinetic traces of the XAS at $709 \mathrm{eV}$ are shown in Fig. 3(a) and (b). To avoid possible artificial effects resulting from the long-term fluctuations at the XFEL, we sequentially recorded the photoexcited signal and the reference signal (at a delay time of $-10 \mathrm{ps}$ ) for each delay time. For shorter delay times,
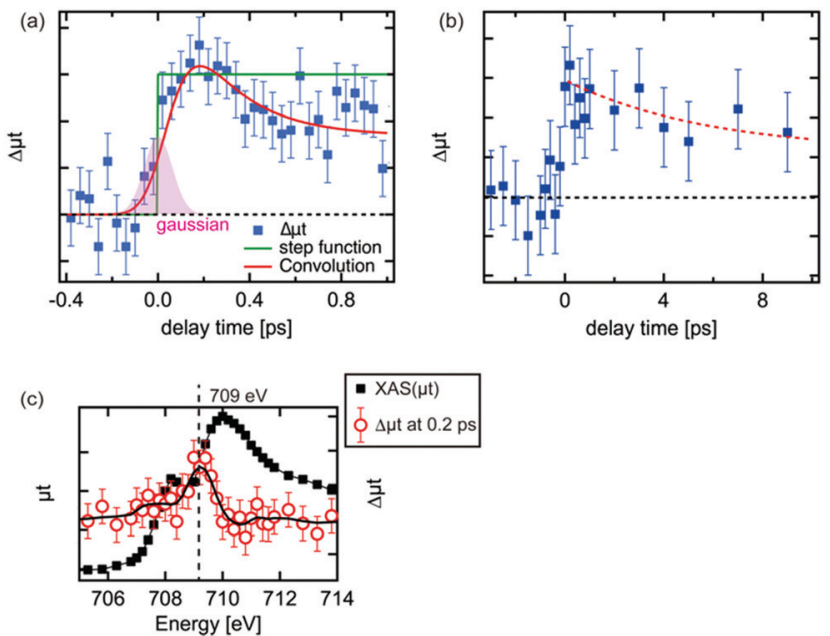

Fig. 3 The kinetic traces of the transient XAS at $709 \mathrm{eV}$. (a) From a delay time of -0.4 ps to that of $1.0 \mathrm{ps}$, (b) from a delay time of $-3 \mathrm{ps}$ to that of $10 \mathrm{ps}$, (c) Fe $\mathrm{L}_{3} \mathrm{XAS}$ and the transient XAS spectrum at $0.2 \mathrm{ps}$. 
the kinetic trace was observed between $-0.4 \mathrm{ps}$ and $1.0 \mathrm{ps}$. The transient signal increased upon irradiation by the laser pulses. In order to estimate the time resolution of the experimental setup, the rise of the transient signal was fitted with a convolution of a step function and a Gaussian function. The time resolution for the experiments was estimated to be $180 \mathrm{fs}$ by the full width of half maximum (FWHM) of the Gaussian function. The estimated value in the experiment seems to be reasonable considering the laser pulse duration ( $\sim 50 \mathrm{fs})$, the pulse duration of X-ray ( $<100 \mathrm{fs})$ and the jitter between the optical laser and the XFEL, although this value is slightly shorter from the time resolution estimated by the change of the reflectance of the laser pulse from a YAG single crystal. ${ }^{33}$ It should be noted that an arrival timing tool or a timing compensation tool is yet to be installed in the beamline. ${ }^{52,53}$ As a result, a precise measurement of the delay time between each X-ray pulse and optical laser pulse or the compensation of the timing drift between them could not be performed. Therefore, we measured the position of the delay stage for a delay time of $0 \mathrm{ps}$ at the beginning and the end of each $12 \mathrm{~h}$ shift. Based on these measurements, we have established that the position for a delay time 0 did not shift by more than 100 fs. Hence, we concluded that there is no significant timing drift on a time scale of $12 \mathrm{~h}$.

The decay process shown in Fig. 3(a) is a fast decay process, whose kinetic constant $(1 / k)$ is $\sim 0.2 \pm 0.1$ ps based on the fit on the decrease of the intensity of the transient signal. A fast process within 1 ps after photoexcitation was observed by several research groups ${ }^{43,44}$ and similar values for the process were proposed $\left(0.24 \mathrm{ps},{ }^{44} 0.25 \mathrm{ps}^{43}\right)$. The kinetic trace in Fig. 3(a) in the longer delay times $(>0.2 \mathrm{ps})$ was fitted well with a convolution of a Gaussian function (FWHM: $0.18 \mathrm{ps}$ ) and an exponential function $(f(t)=A \times \exp (-t / k)+B$, where $A$ and $B$ are arbitrary constants). Considering our experimental conditions, the fast process we observed should correspond to the fast process observed in the previous studies. ${ }^{4-44}$ This process is ascribed to be a relaxation process of the excited electrons in higher energy states to the bottom of the conduction band. ${ }^{42,44}$

For delay times over $1 \mathrm{ps}$, the peak intensity of the difference signal gradually decreased as in Fig. 3(b). The kinetic trace in Fig. 3(b) was fitted as a single exponential function and its kinetic constant of the decay process (1) was estimated to be $\sim 6$ ps. A similar time constant was observed in optical spectroscopy, ${ }^{43}$ which was claimed to be a recombination process between the relaxed electrons and the holes, while such process was not found in the XUV spectroscopies. ${ }^{41,44}$

The electronic structure of the iron sites in transition metal oxides such as $\alpha-\mathrm{Fe}_{2} \mathrm{O}_{3}$ is described by charge transfer multiplet theory, where the ground state of $\mathrm{Fe}$ in $\alpha-\mathrm{Fe}_{2} \mathrm{O}_{3}$ is described as $\left|3 d^{5}+3 d^{6} \underline{L}\right\rangle$. The $3 d^{5}$ configuration represents the ground state of $\mathrm{Fe}(\mathrm{III})$ and " $3 \mathrm{~d}^{6} \underline{\mathrm{L}}$ " represents the state where one electron is excited from $\mathrm{O} 2 \mathrm{p}$ to $\mathrm{Fe} 3 \mathrm{~d}$ with a charge transfer energy ( 4 ) that is different from the band gap due to strong correlation effects. The ground state is the bonding combination of both configurations. Upon optical laser excitation, a valence electron is excited into the conduction band, which in the CTM model refers to an anti-bonding state $\left|3 d^{6} \underline{L}+3 d^{5}\right\rangle$. For simplicity we approximate the ground state and laser excited state to be $\left|3 d^{5}\right\rangle$ and $\left|3 d^{6} \underline{L}\right\rangle$ respectively, keeping in mind that both states are mixed. In addition, the $\left|3 d^{6} \underline{L}\right\rangle_{R}$ and $\left|3 d^{6} \underline{L}\right\rangle_{R^{\prime}}$ states represent the relaxed states from the initial excitation. The overall process can then be described as:

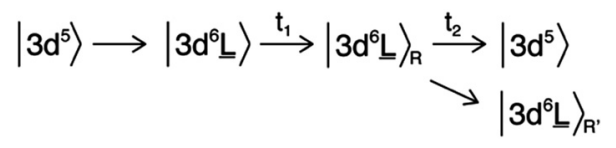

where $t_{1}=0.2 \mathrm{ps}$ and $t_{2}=6 \mathrm{ps}$. In the $2 \mathrm{p}$ XAS process each state $3 \mathrm{~d}^{N}$ is excited to a final state $2 \mathrm{p}^{5} 3 \mathrm{~d}^{N+1}$, where the spectral shape of the anti-bonding $\left|3 d^{6} \underline{L}\right\rangle$ state will have a $\left|2 p^{5} 3 d^{7} \underline{L}\right\rangle$ final state similar to a $\mathrm{Fe}(\mathrm{II})$ ground state. This justifies the first-order approximation of its spectral shape that is related to a $\mathrm{Fe}$ (II) species in the local electronic structure of $\alpha-\mathrm{Fe}_{2} \mathrm{O}_{3}$.

\section{2p3d resonant inelastic scattering of photoexcited hematite}

2p3d RIXS measures the $2 p$ XAS excitation of the $3 d^{5}$ ground state to $2 \mathrm{p}^{5} 3 \mathrm{~d}^{6}$, followed by the decay back to the $3 \mathrm{~d}^{5}$ manifold. A recent static 2p3d RIXS study of $\alpha-\mathrm{Fe}_{2} \mathrm{O}_{3}$ has been published by Miyawaki et al. ${ }^{54}$ We note that the lifetime of the 2 p core hole state is $\sim 10 \mathrm{fs}$ based on its lifetime broadening. We assume that the $2 \mathrm{p}$ core hole decay is faster than any other reorganisation process and that 2p3d RIXS is effectively an instantaneous probe.

The 2p3d RIXS spectra were measured at $710 \mathrm{eV}$, i.e. at the maximum of the static $\alpha-\mathrm{Fe}_{2} \mathrm{O}_{3}$ 2p XAS spectrum. The delay times of each measurement were 1 ps and 10 ps as shown in Fig. 4. The RIXS spectra were normalised to the intensity of elastic X-ray peak (energy loss $\left(E_{\text {loss }}\right) \sim 0 \mathrm{eV}$ ). Each RIXS spectrum was recorded in two hours. Due to the increased possibility for time drift in the delay times around $0.2 \mathrm{ps}$, we could not record the RIXS spectrum for such short delay times. In addition, in order to guarantee that RIXS from photoexcited states are observed, the kinetic traces at $709 \mathrm{eV}$ were observed before each RIXS measurement (Fig. 4).

When we compared the transient RIXS at a delay time of 1 ps to that of $10 \mathrm{ps}$, we noticed that the overall difference signal seemed to increase in the later delay time. We are not certain about the interpretation of this effect due to the low energy resolution of the spectra and the interference between $\mathrm{Fe}$ (II) and $\mathrm{Fe}(\mathrm{III})$ features. One possible explanation could be the longlife time of the $\mathrm{Fe}(\mathrm{II})$ excited states that are generated at hematite defect sites. We observed in another related timeresolved XUV study that these states could have a life time of up to $\sim 350$ ps. It is possible that the concentration of these states increases over time after subsequent optical excitations, which could be reflected in the increase of the difference signal in RIXS at 10 ps.

Examining the time evolution of the RIXS difference signals showed spectral changes in the coloured areas at between $-3 \mathrm{eV}$ and $-8 \mathrm{eV}$. The theoretical 2p3d RIXS spectrum of $\mathrm{Fe}(\mathrm{III})$ contains an elastic peak and a range of $\mathrm{d}-\mathrm{d}$ excitations between -2 and $-7 \mathrm{eV}$ (Fig. 4). The ratio between both the RIXS spectra is given by the excitation energy, essentially as given by the XAS calculations. This implies that Fe(III) has $\sim 10$ times more intensity than $\mathrm{Fe}(\mathrm{II})$. The spectrum of $\mathrm{Fe}(\mathrm{II})$ has a strong 


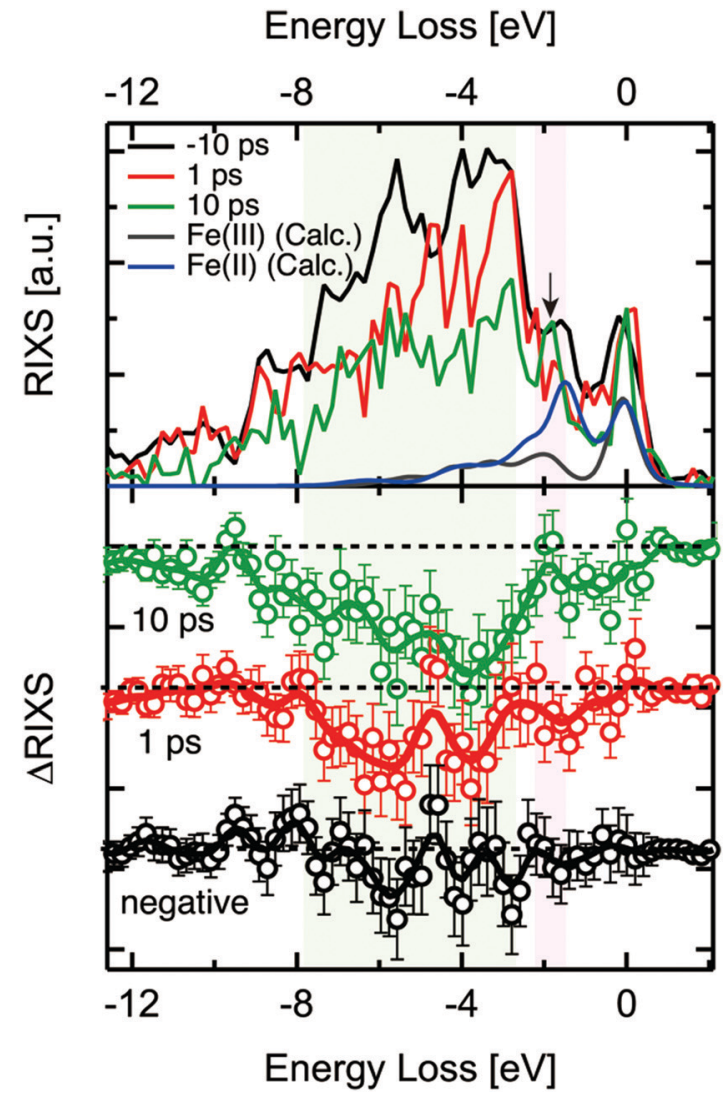

Fig. 4 2p3d RIXS spectra for -10 ps, 1 ps, 10 ps (top) and the difference RIXS spectrum for each delay time (bottom). The incident X-ray energy was $710 \mathrm{eV}$. The calculated spectra were normalised so that their elastic scattering intensities were half of the experimental spectra for clarity.

peak at $\sim 1.8 \mathrm{eV}$ related to the ${ }^{5} \mathrm{~T}_{2} \rightarrow{ }^{5} \mathrm{~T}_{1} \mathrm{~d}-\mathrm{d}$ transition, which will compensate the intensity loss of $\mathrm{Fe}(\mathrm{III})$ at $\sim 1.8 \mathrm{eV}$, implying that only between -3 and $-8 \mathrm{eV}$ intensity is lost. We note that an excitation energy of $710 \mathrm{eV}$, more than $\sim 90 \%$ of the signal is related to $\mathrm{Fe}(\mathrm{III})$ based on the theoretical 2p XAS spectral shapes, which implies that we mainly see Fe(III) in the $2 \mathrm{p} 3 \mathrm{~d}$ RIXS. One could also look specifically at the Fe(II) species, but this would require comparing the RIXS spectra recorded at the excitation energy of $710 \mathrm{eV}$ as well as that of $709 \mathrm{eV}$, which was not measured due to the time constraints. We essentially observe a decrease of the region between -2 and $-7 \mathrm{eV}$ indicating that the amount of $\mathrm{Fe}$ (III) species is reduced. The data quality unfortunately does not allow us to make more specific statements regarding the 2p3d RIXS spectral shapes.

We note that by measuring the 2p3d RIXS at $709 \mathrm{eV}$ we would specifically target the transient $\mathrm{Fe}(\mathrm{II})$ species. Its $2 \mathrm{p} 3 \mathrm{~d}$ RIXS spectrum would reveal its d-d excitations and as such the nature of its state in much more details compared to 2p XAS. In addition there would be much less signal related to the $\mathrm{Fe}(\mathrm{III})$ species.

\section{Photoexcited states of hematite}

It has been proposed that several different excited states exist for the photo-absorption process in hematite by optical spectroscopy. ${ }^{43}$
From our XAS and RIXS results we expect three different excited states in the first $10 \mathrm{ps,}$, in line with the observed states proposed by optical spectroscopic measurements. The initial photoexcited state was observed at a delay time of 0.2 ps. After photoabsorption, the $3 \mathrm{~d}^{5}$ ground state of $\mathrm{Fe}(\mathrm{III})$ is excited to the $3 \mathrm{~d}^{6} \underline{\mathrm{L}}$ charge transfer state. The charge transfer state symmetry is similar to that of a Fe(II) ground state and results in transient peak at $709 \mathrm{eV}$. In a single particle picture, the $3 \mathrm{~d}^{6} \underline{\mathrm{L}}$ state can be interpreted as an electron in the conduction band coupled to a hole in the valence band (Fig. 5). Since the wavelength of the optical laser is larger than the band gap of hematite, the excited electrons and holes have excess energy (often known as hot carriers). The hot electron-hole excitations relate to hot electrons and holes which are distributed in the conduction and valence bands, respectively. The transient signal intensity at $709 \mathrm{eV}$ decreases after $1 \mathrm{ps}$, which corresponds to the relaxation process of the hot carriers. During the relaxation of the hot carriers, the hot electrons relax to the bottom of the conduction band while the holes relax to the top of the valence band releasing extra energy. The fast decay in Fig. 2 and the simulation of the difference spectra in Fig. 3 agree with this hypothesis. During the relaxation the local structure of the Fe atoms is affected, which modifies the $\mathrm{Fe}-\mathrm{O}$ and $\mathrm{Fe}-\mathrm{Fe}$ bond distances. These structural changes affect the electronic structure $\left(10 \Delta_{\mathrm{q}}\right.$, etc.) of the excited $\mathrm{Fe}$ atoms, thereby also changing the $\mathrm{Fe} \mathrm{L}_{3}$ XAS spectral shape.

The transient signal intensity decreased further after $10 \mathrm{ps,}$ which agrees with the charge recombination process observed in optical spectroscopy. The population of the excited electrons is decreased by the recombination events, i.e. by the decay of anti-bonding $3 \mathrm{~d}^{6} \underline{\mathrm{L}}$ to bonding $3 \mathrm{~d}^{5}$ states. The intensity of the
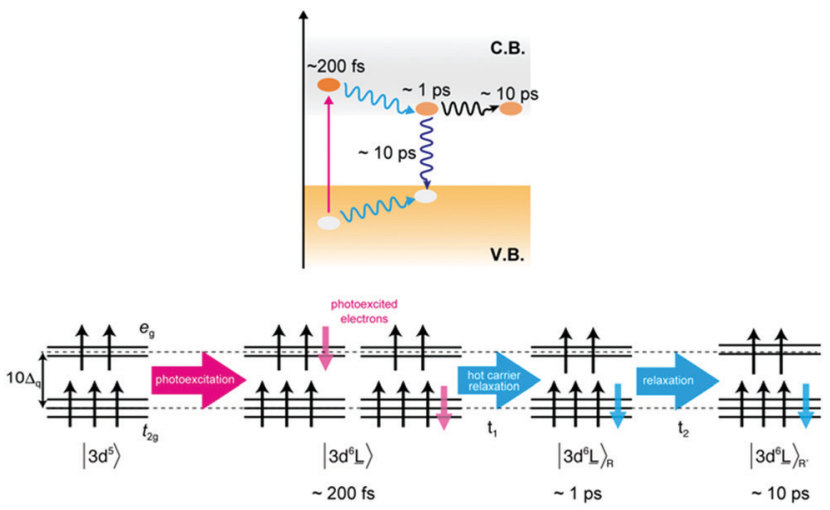

Fig. 5 Schematic diagram of the possible pathways of the excited states of hematite upon visible light excitation. Before photoexcitation $\left(\left|3 d^{5}\right\rangle\right)$, the valence of $\mathrm{Fe}$ is $3+$, which has 5 electrons in the $3 \mathrm{~d}$ orbitals. The $3 \mathrm{~d}$ orbitals of Fe are split into $3 \mathrm{t}_{\mathrm{g}}$ orbitals and $2 \mathrm{e}_{\mathrm{g}}$ orbitals because of its octahedral symmetry. After photoexcitation $\left(\left|3 \mathrm{~d}^{6} \underline{\mathrm{L}}\right\rangle, \sim 200 \mathrm{fs}\right)$, an excited electron occupies $t_{g}$ or $e_{g}$ orbitals. Within $1 \mathrm{ps}\left(\left|3 d^{6} \underline{L}\right\rangle_{R^{\prime}} \sim 1 \mathrm{ps}\right)$, the excited electron relaxes to occupy the $t_{g}$ orbital. In the later delay time ( $\left.\sim 10 \mathrm{ps}\right)$, some of the excited Fe species change to another excited state $\left(\left|3 d^{6} \underline{L}\right\rangle_{R^{\prime}}\right)$ while others relax to the ground state. It is noted that the excited electron is spin-down because the spin-up states are all occupied. At a neighboring site, the spin-up and spin-down signature is reversed as $\alpha-\mathrm{Fe}_{2} \mathrm{O}_{3}$ is an antiferromagnet. 
difference spectra at $709 \mathrm{eV}$ is attributed to the number of $\mathrm{Fe}(\mathrm{II})$ atoms and the decrease of $\mathrm{Fe}(\mathrm{II})$ atoms leads to the reduction of the difference signals around 10 ps. Interestingly, we observe that the $\mathrm{Fe}(\mathrm{II})$ species remains present for several hundreds of picoseconds.

\section{Conclusions}

In this study, we have reported the first femtosecond $\mathrm{Fe}_{3} \mathrm{XAS}$ and femtosecond 2p3d RIXS of hematite using the PAL-XFEL. Upon photoexcitation, electrons are transferred from the hematite valence band (mainly $\mathrm{O} 2 \mathrm{p}$ ) to the conduction band (mainly Fe 3d). We detected three relaxation events after photoexcitation: the first process is the relaxation of hot electrons to a lower energy state. This relaxation process of the hot carriers with a kinetic constant of 0.2 ps was observed by $\mathrm{Fe}_{3}$ XAS with a time resolution of $180 \mathrm{fs}$. The second process is a fast carrier recombination, which was observed as the decrease of the transient XAS signal at $709 \mathrm{eV}$ with a kinetic constant of $6 \mathrm{ps}$. In this process, part of the Fe(II)-like species relaxed back to $3 \mathrm{~d}^{5} \mathrm{Fe}(\mathrm{III})$. However, our observations also show that some $\mathrm{Fe}(\mathrm{II})$ species remain a longer time scale (in Fig. S2 in ESI†). This long-living photoexcited state could be a trapping state of the excited electrons with a local structural change around photoexcited iron atoms in hematite to form small polarons.

To the best of our knowledge, this is the first report on femtosecond transient RIXS of a solid-state material. Our result demonstrates exciting possibilities for studying the photoexcited states of solid-state materials using femtosecond RIXS. In future experiments, where RIXS spectra will be measured at different excitation energies and better energy resolution, more detailed information will be revealed about specific electronic states of the photoexcited materials. It could also be possible to describe charge carrier dynamics in ultrafast time scales with electronic configurations at each distinctive delay time.

Although there have been several pioneering works of timeresolved 2p3d RIXS, ${ }^{24-30}$ the opportunity to perform time-resolved 2p3d RIXS experiments was limited since only the Linac Coherent Light Source (LCLS, Menlo Park, CA, USA) was able to provide the soft X-rays needed. ${ }^{55,56}$ In addition to the Pohang XFEL, new soft X-ray beamlines are being implemented in novel XFEL facilities such as in LCLS-II, ${ }^{57}$ European XFEL ${ }^{33}$ and Swiss FEL. ${ }^{36}$ Such powerful FEL facilities, providing ultrashort soft X-ray pulses, will make it possible to address structural and electronic configurations of excited states of semiconductors consisting of 3d transition metals thereby opening possibilities to understand the mechanism of e.g. a solar-assisting water splitting reaction.

\section{Conflicts of interest}

There are no conflicts to declare.

\section{Acknowledgements}

This work was financially supported by the European Research Council (ERC) under the European Union's Horizon 2020 research and innovation programme (grant agreement No 340279), Netherlands Center for Multiscale Catalytic Energy Conversion (MCEC), a Gravitation Program from the Netherlands Organisation for Scientific Research (NWO), Grant for collaborative research in Institute for Catalysis, Hokkaido University (18A1005) and a basic science research program funded by the Ministry of Education, Government of the Netherlands (No. NRF-2017R1D1A1A02018484). This work was carried out by the joint research in the Synchrotron Radiation Research Organization and the Institute for Solid State Physics, the University of Tokyo (Proposal No. 2019A7592). The experiments were performed at SSS end-station of PAL-XFEL (proposal no. 2018-2nd-SSS-001 or 2019-1st-SSS-020) funded by the Ministry of Science and ICT of Korea.

\section{References}

1 M. Chergui and E. Collet, Chem. Rev., 2017, 117, 11025-11065.

2 C. J. Milne, T. J. Penfold and M. Chergui, Coord. Chem. Rev., 2014, 277-278, 44-68.

3 C. Bressler and M. Chergui, Annu. Rev. Phys. Chem., 2010, 61, 263-282.

4 C. Bressler and M. Chergui, Chem. Rev., 2004, 104, 1781-1812.

5 Y. Iwasawa, K. Asakura and M. Tada, XAFS Techniques for Catalysts, Nanomaterials, and Surfaces, Springer International Publishing, 2017.

6 J. A. Van Bokhoven and C. Lamberti, X-Ray Absorption and $X$-Ray Emission Spectroscopy: Theory and Applications, John Wiley \& Sons, UK, 2016.

7 T. J. Penfold, J. Szlachetko, F. G. Santomauro, A. Britz, W. Gawelda, G. Doumy, A. M. March, S. H. Southworth, J. Rittmann, R. Abela, M. Chergui and C. J. Milne, Nat. Commun., 2018, 9, 478.

8 T. J. Penfold, S. Karlsson, G. Capano, F. A. Lima, J. Rittmann, M. Reinhard, M. H. Rittmann-Frank, O. Braem, E. Baranoff, R. Abela, I. Tavernelli, U. Rothlisberger, C. J. Milne and M. Chergui, J. Phys. Chem. A, 2013, 117, 4591-4601.

9 Y. Uemura, D. Kido, A. Koide, Y. Wakisaka, Y. Niwa, S. Nozawa, K. Ichiyanagi, R. Fukaya, S. Adachi, T. Katayama, T. Togashi, S. Owada, M. Yabashi, K. Hatada, A. Iwase, A. Kudo, S. Takakusagi, T. Yokoyamaa and K. Asakura, Chem. Commun., 2017, 53, 7314-7317.

10 Y. Obara, H. Ito, T. Ito, N. Kurahashi, S. Thürmer, H. Tanaka, T. Katayama, T. Togashi, S. Owada, Y.-I. Yamamoto, S. Karashima, J. Nishitani, M. Yabashi, T. Suzuki and K. Misawa, Struct. Dyn., 2017, 4, 044033.

11 Y. Uemura, D. Kido, Y. Wakisaka, H. Uehara, T. Ohba, Y. Niwa, S. Nozawa, T. Sato, K. Ichiyanagi, R. Fukaya, S.-I. Adachi, T. Katayama, T. Togashi, S. Owada, K. Ogawa, M. Yabashi, K. Hatada, S. Takakusagi, T. Yokoyama, B. Ohtani and K. Asakura, Angew. Chem., Int. Ed., 2016, 55, 1364-1367.

12 D. Hayes, R. G. Hadt, J. D. Emery, A. A. Cordones, A. B. F. Martinson, M. L. Shelby, K. A. Fransted, P. D. Dahlberg, J. Hong, X. Zhang, Q. Kong, R. W. Schoenlein and L. X. Chen, Energy Environ. Sci., 2016, 9, 3754-3769.

13 H. Wen, M. Sassi, Z. Luo, C. Adamo, D. G. Schlom, K. M. Rosso and X. Zhang, Sci. Rep., 2015, 5, 15098. 
14 F. G. Santomauro, A. Lübcke, J. Rittmann, E. Baldini, A. Ferrer, M. Silatani, P. Zimmermann, S. Grübel, J. A. Johnson, S. O. Mariager, P. Beaud, D. Grolimund, C. Borca, G. Ingold, S. L. Johnson and M. Chergui, Sci. Rep., 2015, 5, 14834.

15 Y. Uemura, H. Uehara, Y. Niwa, S. Nozawa, T. Sato, S. Adachi, B. Ohtani, S. Takakusagi and K. Asakura, Chem. Lett., 2014, 43, 977-979.

16 M. H. Rittmann-Frank, C. J. Milne, J. Rittmann, M. Reinhard, T. J. Penfold and M. Chergui, Angew. Chem., Int. Ed., 2014, 53, 5858-5862.

17 N. A. Miller, A. Deb, R. Alonso-Mori, B. D. Garabato, J. M. Glownia, L. M. Kiefer, J. Koralek, M. Sikorski, K. G. Spears, T. E. Wiley, D. Zhu, P. M. Kozlowski, K. J. Kubarych, J. E. Penner-Hahn and R. J. Sension, J. Am. Chem. Soc., 2017, 139, 1894-1899.

18 H. T. Lemke, K. S. Kjaer, R. Hartsock, T. B. van Driel, M. Chollet, J. M. Glownia, S. Song, D. Zhu, E. Pace, S. F. Matar, M. M. Nielsen, M. Benfatto, K. J. Gaffney, E. Collet and M. Cammarata, Nat. Commun., 2017, 8, 15342.

19 M. L. Shelby, P. J. Lestrange, N. E. Jackson, K. Haldrup, M. W. Mara, A. B. Stickrath, D. Zhu, H. T. Lemke, M. Chollet, B. M. Hoffman, X. Li and L. X. Chen, J. Am. Chem. Soc., 2016, 138, 8752-8764.

20 H. T. Lemke, C. Bressler, L. X. Chen, D. M. Fritz, K. J. Gaffney, A. Galler, W. Gawelda, K. Haldrup, R. W. Hartsock, H. Ihee, J. Kim, K. H. Kim, J. H. Lee, M. M. Nielsen, A. B. Stickrath, W. Zhang, D. Zhu and M. Cammarata, J. Phys. Chem. A, 2013, 117, 735-740.

21 S. E. Canton, K. S. Kjær, G. Vankó, T. B. van Driel, S.-I. Adachi, A. E. Bordage, C. Bressler, P. Chabera, M. Christensen, A. O. Dohn, A. Galler, W. Gawelda, D. Gosztola, K. Haldrup, T. Harlang, Y. Liu, K. B. Móller, Z. Németh, S. Nozawa, M. Pápai, T. Sato, T. Sato, K. Suarez-Alcantara, T. Togashi, K. Tono, J. Uhlig, D. A. Vithanage, K. Wärnmark, M. Yabashi, J. Zhang, V. Sundström and M. M. Nielsen, Nat. Commun., 2015, 6, 6359.

22 K. Haldrup, W. Gawelda, R. Abela, R. Alonso-Mori, U. Bergmann, A. Bordage, M. Cammarata, S. E. Canton, A. O. Dohn, T. B. van Driel, D. M. Fritz, A. Galler, P. Glatzel, T. Harlang, K. S. Kjær, H. T. Lemke, K. B. Móller, Z. Németh, M. Pápai, N. Sas, J. Uhlig, D. Zhu, G. Vankó, V. Sundström, M. M. Nielsen and C. Bressler, J. Phys. Chem. B, 2016, 120, 1158-1168.

23 J. Kern, R. Tran, R. Alonso-Mori, S. Koroidov, N. Echols, J. Hattne, M. Ibrahim, S. Gul, H. Laksmono, R. G. Sierra, R. J. Gildea, G. Han, J. Hellmich, B. Lassalle-Kaiser, R. Chatterjee, A. S. Brewster, C. A. Stan, C. Glöckner, A. Lampe, D. DiFiore, D. Milathianaki, A. R. Fry, M. M. Seibert, J. E. Koglin, E. Gallo, J. Uhlig, D. Sokaras, T.-C. Weng, P. H. Zwart, D. E. Skinner, M. J. Bogan, M. Messerschmidt, P. Glatzel, G. J. Williams, S. Boutet, P. D. Adams, A. Zouni, J. Messinger, N. K. Sauter, U. Bergmann, J. Yano and V. K. Yachandra, Nat. Commun., 2014, $5,4371$.

24 M. Beye, F. Sorgenfrei, W. F. Schlotter, W. Wurth and A. Föhlisch, Proc. Natl. Acad. Sci. U. S. A., 2010, 107, 16772-16776.
25 R. M. Jay, S. Eckert, M. Fondell, P. S. Miedema, J. Norell, A. Pietzsch, W. Quevedo, J. Niskanen, K. Kunnus and A. Föhlisch, Phys. Chem. Chem. Phys., 2018, 20, 27745-27751. 26 R. M. Jay, J. Norell, S. Eckert, M. Hantschmann, M. Beye, B. Kennedy, W. Quevedo, W. F. Schlotter, G. L. Dakovski, M. P. Minitti, M. C. Hoffmann, A. Mitra, S. P. Moeller, D. Nordlund, W. Zhang, H. W. Liang, K. Kunnus, K. Kubicek, S. A. Techert, M. Lundberg, P. Wernet, K. Gaffney, M. Odelius and A. Föhlisch, J. Phys. Chem. Lett., 2018, 9, 3538-3543.

27 K. Kunnus, I. Josefsson, I. Rajkovic, S. Schreck, W. Quevedo, M. Beye, C. Weniger, S. Grübel, M. Scholz, D. Nordlund, W. Zhang, R. W. Hartsock, K. J. Gaffney, W. F. Schlotter, J. J. Turner, B. Kennedy, F. Hennies, F. M. F. de Groot, S. Techert, M. Odelius, P. Wernet and A. Föhlisch, Struct. Dyn., 2016, 3, 043204.

28 J. Norell, R. M. Jay, M. Hantschmann, S. Eckert, M. Guo, K. J. Gaffney, P. Wernet, M. Lundberg, A. Föhlisch and M. Odelius, Phys. Chem. Chem. Phys., 2018, 20, 7243-7253.

29 V. Vaz da Cruz, F. Gel'mukhanov, S. Eckert, M. Iannuzzi, E. Ertan, A. Pietzsch, R. C. Couto, J. Niskanen, M. Fondell, M. Dantz, T. Schmitt, X. Lu, D. McNally, R. M. Jay, V. Kimberg, A. Föhlisch and M. Odelius, Nat. Commun., 2019, 10, 1013.

30 P. Wernet, K. Kunnus, I. Josefsson, I. Rajkovic, W. Quevedo, M. Beye, S. Schreck, S. Grubel, M. Scholz, D. Nordlund, W. Zhang, R. W. Hartsock, W. F. Schlotter, J. J. Turner, B. Kennedy, F. Hennies, F. M. de Groot, K. J. Gaffney, S. Techert, M. Odelius and A. Fohlisch, Nature, 2015, 520, 78-81.

31 H.-S. Kang, C.-K. Min, H. Heo, C. Kim, H. Yang, G. Kim, I. Nam, S. Y. Baek, H.-J. Choi, G. Mun, B. R. Park, Y. J. Suh, D. C. Shin, J. Hu, J. Hong, S. Jung, S.-H. Kim, K. Kim, D. Na, S. S. Park, Y. J. Park, J.-H. Han, Y. G. Jung, S. H. Jeong, H. G. Lee, S. Lee, S. Lee, W.-W. Lee, B. Oh, H. S. Suh, Y. W. Parc, S.-J. Park, M. H. Kim, N.-S. Jung, Y.-C. Kim, M.-S. Lee, B.-H. Lee, C.-W. Sung, I.-S. Mok, J.-M. Yang, C.-S. Lee, H. Shin, J. H. Kim, Y. Kim, J. H. Lee, S.-Y. Park, J. Kim, J. Park, I. Eom, S. Rah, S. Kim, K. H. Nam, J. Park, J. Park, S. Kim, S. Kwon, S. H. Park, K. S. Kim, H. Hyun, S. N. Kim, S. Kim, S.-M. Hwang, M. J. Kim, C.-y. Lim, C.-J. Yu, B.-S. Kim, T.-H. Kang, K.-W. Kim, S.-H. Kim, H.-S. Lee, H.-S. Lee, K.-H. Park, T.-Y. Koo, D.-E. Kim and I. S. Ko, Nat. Photonics, 2017, 11, 708-713. 32 PAL-XFEL, http://pal.postech.ac.kr/paleng/.

33 S. H. Park, M. Kim, C.-K. Min, I. Eom, I. Nam, H.-S. Lee, H.-S. Kang, H.-D. Kim, H. Y. Jang, S. Kim, S.-M. Hwang, G.-S. Park, J. Park, T.-Y. Koo and S. Kwon, Rev. Sci. Instrum., 2018, 89, 055105.

34 L. J. P. Ament, M. van Veenendaal, T. P. Devereaux, J. P. Hill and J. van den Brink, Rev. Mod. Phys., 2011, 83, 705-767.

35 F. de Groot and A. Kotani, Core Level Spectroscopy of Solids, CRC Press, 2008.

36 A. Kotani and S. Shin, Rev. Mod. Phys., 2001, 73, 203-246. 37 K. Sivula, F. L. Formal and M. Grätzel, ChemSusChem, 2011, 4, 432-449.

38 A. G. Tamirat, J. Rick, A. A. Dubale, W.-N. Su and B.-J. Hwang, Nanoscale Horiz., 2016, 1, 243-267. 
39 M. Barroso, S. R. Pendlebury, A. J. Cowan and J. R. Durrant, Chem. Sci., 2013, 4, 2724-2734.

40 A. Kay, I. Cesar and M. Grätzel, J. Am. Chem. Soc., 2006, 128, 15714-15721.

41 J. Husek, A. Cirri, S. Biswas and L. R. Baker, Chem. Sci., 2017, 8, 8170-8178.

42 S. R. Pendlebury, X. Wang, F. L. Formal, M. Cornuz, A. Kafizas, S. D. Tilley, M. Grätzel and J. R. Durrant, J. Am. Chem. Soc., 2014, 136, 9854-9857.

43 S. Sorenson, E. Driscoll, S. Haghighat and J. M. Dawlaty, J. Phys. Chem. C, 2014, 118, 23621-23626.

44 J. Vura-Weis, C.-M. Jiang, C. Liu, H. Gao, J. M. Lucas, F. M. F. de Groot, P. Yang, A. P. Alivisatos and S. R. Leone, J. Phys. Chem. Lett., 2013, 4, 3667-3671.

45 L. M. Carneiro, S. K. Cushing, C. Liu, Y. Su, P. Yang, A. P. Alivisatos and S. R. Leone, Nat. Mater., 2017, 16, 819-825.

46 A. J. E. Rettie, W. D. Chemelewski, D. Emin and C. B. Mullins, J. Phys. Chem. Lett., 2016, 7, 471-479.

47 K. Takubo, K. Yamamoto, Y. Hirata, Y. Yokoyama, Y. Kubota, S. Yamamoto, S. Yamamoto, I. Matsuda, S. Shin, T. Seki, K. Takanashi and H. Wadati, Appl. Phys. Lett., 2017, 110, 162401.

48 SPring-8 several bunch modes, http://www.spring8.or.jp/en/ users/operation_status/schedule/bunch_mode_b19/.
49 M. U. Delgado-Jaime, K. Zhang, J. Vura-Weis and F. M. F. de Groot, J. Synchrotron Radiat., 2016, 23, 1264-1271.

50 M. W. Haverkort, M. Zwierzycki and O. K. Andersen, Phys. Rev. B: Condens. Matter Mater. Phys., 2012, 85, 165113.

51 B. Liu, C. Piamonteze, M. U. Delgado-Jaime, R.-P. Wang, J. Heidler, J. Dreiser, R. Chopdekar, F. Nolting and F. M. F. de Groot, Phys. Rev. B, 2017, 96, 054446.

52 M. R. Bionta, N. Hartmann, M. Weaver, D. French, D. J. Nicholson, J. P. Cryan, J. M. Glownia, K. Baker, C. Bostedt, M. Chollet, Y. Ding, D. M. Fritz, A. R. Fry, D. J. Kane, J. Krzywinski, H. T. Lemke, M. Messerschmidt, S. Schorb, D. Zhu, W. E. White and R. N. Coffee, Rev. Sci. Instrum., 2014, 85, 083116.

53 T. Katayama, S. Owada, T. Togashi, K. Ogawa, P. Karvinen, I. Vartiainen, A. Eronen, C. David, T. Sato, K. Nakajima, Y. Joti, H. Yumoto, H. Ohashi and M. Yabashi, Struct. Dyn., 2016, 3, 034301.

54 J. Miyawaki, S. Suga, H. Fujiwara, M. Urasaki, H. Ikeno, H. Niwa, H. Kiuchi and Y. Harada, Phys. Rev. B, 2017, 96, 214420.

55 T. Funk, A. Deb, S. J. George, H. Wang and S. P. Cramer, Coord. Chem. Rev., 2005, 249, 3-30.

56 X. Liu, W. Yang and Z. Liu, Adv. Mater., 2014, 26, 7710-7729. 57 LCLS-II, https://lcls.slac.stanford.edu/lcls-ii. 